\title{
Vasculonecrotic Reactions in Leprosy
}

Letícia Fogagnolo ${ }^{1}$, Elemir Macedo de Souza ${ }^{1}$, Maria Letícia Cintra ${ }^{2}$ and Paulo Eduardo Neves Ferreira Velho ${ }^{1}$ ${ }^{\prime}$ Departments of Dermatology and ${ }^{2}$ Pathology, Medical School, State University of Campinas (Unicamp); Campinas, SP, Brazil

\begin{abstract}
Multibacillary, lepromatous or borderline leprosy patients may present two types of vasculonecrotic reactions: Lucio phenomenon and that associated with erythema nodosum leprosum. Despite they can be distinguished through clinical and histological characteristics; both are often used as synonyms. It is said that leprosy reaction should be properly classified for therapeutic reasons, since it is well known that in Lucio phenomenon there is not a good response to thalidomide. The authors reported two cases of vasculonecrotic phenomena in lepromatous leprosy sharing clinical and histopathological characteristics of both reaction subtypes. The findings may indicate the spectral nature of the reaction phenomena in leprosy and emphasize the importance of the clinic-pathological correlation for proper classification. Our findings may contribute to the understanding of leprosy reactions pathogenesis, broaden the knowledge about their outcome with standard treatment, and provide the scientific background to design better therapeutic strategies for these complications.
\end{abstract}

Key-Words: Leprosy, lepromatous, erythema nodosum, vasculitis.

Leprosy is a disease of slow development that presents a wide spectrum of clinical, histopathological and immunological characteristics [1-4]. Abrupt changes in the clinical stability of the disease, known as leprosy in reaction, depend on immunoallergic phenomena involving antigens of Hansen bacillus [1,4].

Since 1953 two unstable forms of the disease have been recognized, the indeterminate and the dimorphous (currently borderline), in addition to the stable tuberculoid and lepromatous polar forms, previously defined [5,6]. While in the tuberculoid form the body is able to restrict dissemination of the mycobacteria, in the lepromatous form the cellular immunity of the patient is not competent to prevent it. In the dimorphous form, this immunological capability is partial and may either be closer to the lepromatous or to the tuberculoid pole. In the indeterminate form, the disease may progress into one of the forms in this spectrum [3-6].

Leprosy reactions of types I and II also depend on these individual immunological characteristics. In type I the cellular immunity is, at some point, preserved and, consequently the reaction occurs only in those forms closer to the tuberculoid pole. The type II reaction, on the other hand, is characteristic of lepromatous, borderline-lepromatous and borderline leprosy $[1,4,5]$.

In 1852, Raphael Lucio and Ignácio Alvarado, in their report "Opúsculo sobre el mal de San Lazaro o elefantíase de los griecos", described a form of leprosy they called "lazarine leprosy" [7]. In this form there are no localized skin infiltrations. Frequent reaction episodes take place with scarlet spots that later darken and may ulcerate, leaving atrophic and

Received on 12 April 2007; revised 20 May 2007.

Address for correspondence: Dr. Paulo Velho. Department of Internal Medicine (Dermatology), Medical School, State University of Campinas - Unicamp. Cidade Universitária Zeferino Vaz, s/n, 13.081-970, Campinas, SP, Brazil. Phone/Fax: 55-19-3289-4107. E-mail: pvelho@unicamp.br.

The Brazilian Journal of Infectious Diseases

2007;11(3):378-382. (C) 2007 by The Brazilian Journal of Infectious Diseases and Contexto Publishing. All rights reserved. hypochromic scars with a thin hyperpigmented border. The lesions spread in an upward direction, being more frequent on extension surfaces: feet, legs, hands, forearms, arms and rarely on the face and torso. The authors reported, in these patients, tingling of hands and feet, hypo- or anhidrosis, alopecia of eyelashes and eyebrows, smooth and rosy skin. Following this clinical picture, other manifestations include saddle-nose deformity, rhinitis, gastrointestinal, respiratory and circulatory signs, very prominent varicose veins, absence of eye lesions and an absolute absence of nodules [2,7-9]. Latapi and Chevez Zamora, in 1948 [10], added some characteristics to the original Lucio and Alvarado description, calling it Lucio leprosy or pure primitive diffuse leprosy. In the perception of these authors, it was a clinically individualized form within the pole, which nowadays is called lepromatous leprosy. It is more frequent in Mexico and is distinct from the diffuse forms that progress with nodular lesions, since in Lucio leprosy the Virchow cells do not form nodules. The skin presents diffuse infiltration, resulting in a healthy appearance; afterward it becomes myxedematous, especially on the face and hands, and years later it becomes atrophic and ichthyosiform [2,8-11]. Such is the clinical base for the onset of necrotizing spots that constitute the necrotizing erythema or Lucio phenomenon (LP) $[2,8,10]$.

LP is, therefore, described as a necrotizing reactional picture that is present in patients with this pure and primitive form of diffuse leprosy that never evolves with papules, plaques or leprotic nodules. The phenomenon may also occur in the secondary form of Lucio leprosy described by Latapi, where hypochromic spots of indeterminate leprosy precede diffuse skin infiltration [2,8-10].

LP is manifested three to four years after onset of disease $[2,7,8,12,13]$ and is more common in untreated patients or in those receiving inadequate treatment. Six to eight weeks after the beginning of treatment, this phenomenon tends to disappear and, when the patients still present reactions, they are of the erythema nodosum type [8]. The skin lesions are characterized by erythematous spots that progress to superficial 0.5 to $1 \mathrm{~cm}$ lesions of irregular format, more 
frequently triangular, polygonal or angular, with a localized burning sensation. Sometimes blisters appear. The entire phenomenon, from the appearance of the spot until complete elimination of the scar tissue, takes a little longer than fifteen days. The lesions coexist in several evolution stages in the same patient. Between two and four weeks, the healing process of ulcerations begins and a superficial scar is formed [2,8,9,12,14]. The Mitsuda test result is always negative in these patients [8]. Medina test, currently seldom carried out in Brazil, depends on a hypersensitivity reaction and consists in the reproduction of the first phases of LP, 4 to 6 hours after injection of the Mitsuda antigen. In LP patients, Medina reaction is usually positive $[2,4-6,8,15]$. Another point that should be considered in patients with LP-like lesions is the possibility of a conventional lepromatous leprosy, apparently diffuse, but that would later on present lepromas (nodules) [2,9].

The literature review of reaction pictures in leprosy patients shows that there is an inadequate use of this definition. Several authors identify as LP the vasculonecrotic reactions (VN) that occur in other forms than the diffuse, pure (primitive or secondary) leprosy. They describe it in multibacillary patients with type II reaction [14,16-19].

The type II reaction is named erythema nodosum leprosum (ENL), although many times its clinical expression is of erythema multiforme. It occurs in multibacillary, lepromatous or borderline leprosy patients, mainly in the beginning of treatment $[1,6,13,14]$. VN may develop, with deep and severe ulcerations that result in fibrotic, hypertrophic and radiated scars. The lesions are very painful and the preferred places are the face and the limbs. They may be accompanied by fever, despondency, arthralgia, myalgia, leukocytosis, neutrophilia, lymphadenopathy, neuritis, iridocyclitis and orchitis. Contrariwise, these signs and symptoms are very discrete or totally absent in LP. Medina reaction is negative $[6,8,13,14]$. VN in ENL responds well to therapy with thalidomide, contrarily to $\operatorname{LP}[3,15,20]$.

At the histopathological view, in LP, leukocytoclastic vasculitis is observed, superimposed on findings of diffuse lepromatous leprosy. A dense infiltrate of foam histiocytes replaces the dermis and, sometimes, extends to the subcutaneous tissue. In severe ulcerative lesions, the number of acid-fast bacilli is decreased, although they are found in great quantity in the surrounding area, which is customary in this form of leprosy [21]. The histiocytic aggregates, rich in bacilli, go through a process of coagulative necrosis [22]. The affected vessels are the superficial (dermal) ones, in which endothelial proliferation and thrombosis occur. Therefore, ischemic necrosis due to vascular occlusion takes place, resulting in superficial ulcers $[8,9,12,23,24]$.

In the VN of the scarifying forms of ENL, panvasculitis develops, starting in the hypodermis, where the affected vessels are of variable caliber, with larger necrosis resulting in fibrotic scars. Lesion resolution is processed through the healthy surrounding skin and the number of viable bacilli is found to be reduced $[8,21]$.
These data are summarized in Table 1.

We present herein two clinical cases of patients with lepromatous leprosy that developed vasculonecrotic phenomena, sharing clinical and histopathological characteristics of both reaction subtypes.

\section{Case Report 1}

Caucasian 15-y-o-female, using the WHO proposed multidrug therapy regimen for multibacillary leprosy for 1 year. Ever since the beginning of treatment she had presented persistent erythema nodosum reactions and consequently high prednisone doses were prescribed. As familial antecedent there was the information that her father had been treated for multibacillary leprosy. She came to the Dermatology Department with typical herpes zoster lesions on the left side of her lumbar region. She also presented, on her limbs and torso, erythematous and infiltrated lesions, cushingoid facies and striae. Madarosis and infiltration of ear lobes or of the face were absent. A daily oral dose of acyclovir $4.0 \mathrm{~g}$ was prescribed. The patient returned three days later with very painful purplish lesions and skin necrosis of varied sizes scattered over the body, some of them surrounded by a pale border and a few with blisters (Figure 1). She was afebrile. Histological examination revealed necrotizing dermal leukocytoclastic vasculitis with epidermal necrosis in the process of reepithelization and without panniculitis. No masses of Virchow cells were seen in the dermis, only macrophages amid the lymphoid infiltrate (Figure 2). With special staining, numerous whole and fragmented acid-fast bacilli were observed inside the macrophages (bacilloscopic index 5+). She was hospitalized and, after the possibility of pregnancy was ruled out, daily $200 \mathrm{mg}$ oral doses of thalidomide and $80 \mathrm{mg}$ doses of prednisone were prescribed, in addition to a daily $2.25 \mathrm{~g}$ dose of intravenous acyclovir.

Three weeks later the lesions presented involution. She was discharged, thalidomide was suspended and prednisone decreased to $60 \mathrm{mg}$ daily. The multidrug therapy plan already in use was maintained. While in follow-up at the outpatient clinic it was observed that the ulcers were replaced by several oval erythematoviolaceous atrophic scars on the lower and upper limbs.

\section{Case Report 2}

Caucasian 31-y-o male had been followed at another clinic for a clinical picture of recurrent blisters for ten months. He mentioned pain at the beginning, with erythematous lesions and subsequent formation of blisters and ulcers that appeared first on the knees and progressed to upper limbs and abdomen, which improved with prednisone. Simultaneously with this picture he presented nocturnal fever. When he first came to our clinics he complained of new painful lesions and fever for the past week. The lesions evolved with necrotic areas. He denied having had contact with leprosy patients. At the physical examination he presented erythematous/wine colored lesions, several of them with flaccid blisters (sometimes 
Table 1. Comparison between Lucio phenomenon and type II reaction with vasculonecrotic phenomenon

\begin{tabular}{ll}
\hline Luciophenomenon & Type II leprosy reaction with vasculonecrotic phenomenon \\
\hline $\begin{array}{l}\text { Occurs only in the diffuse form of leprosy when no } \\
\text { nodules appear }\end{array}$ & Occurs in leprosy with plaques and nodules \\
$\begin{array}{l}\text { Occurs in untreated individuals, a few years after onset of } \\
\text { disease and disappears with treatment, being sometimes }\end{array}$ & More frequent in the first months of treatment \\
replaced by erythema nodosum & \\
Reddish 0.5 to $1.0 \mathrm{~cm}$ spots that ulcerate & Extensive and deep necrotic lesions \\
Burning sensation & Ischemic pain \\
Usually afebrile & Presents fever \\
Does not affect nerves & It may be accompanied by neuritis \\
No general symptoms or visceral damage & Arthralgia, iridocyclitis, orchitis, lymphadenopathy, nephritis, \\
& hepatitis \\
Positive Medina test & Negative Medina test \\
Superficial leukocytoclastic vasculitis and necrosis & Superficial and deep leukocytoclastic vasculitis and superficial \\
& and deep necrosis; associated erythema nodosum leprosum \\
Does not respond to thalidomide & Responds to thalidomide \\
Resolution in 15 days & Slow resolution \\
Small hypochromic scars with hyperchromic border & Large hypertrophic scars \\
\hline
\end{tabular}

Figure 1. Vasculonecrotic lesions on the upper extremity of a woman with lepromatous leprosy (Case 1).

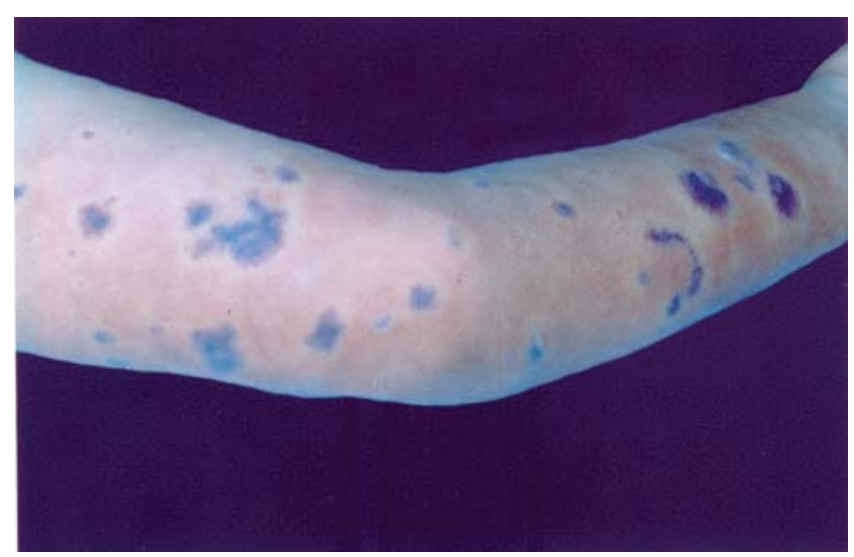

hemorrhagic or seropurulent) and some ulcers with blackened bottoms, others with hematic crusts, irregular borders, increased local temperature and fetid odor. They were scattered on the knees, thighs, abdomen and back surfaces of the upper limbs. There were also scars spread over the body, edema of the lower and upper limbs and absence of madarosis. The hypotheses of paracoccidioidomycosis, tuberculosis and leprosy were considered. A biopsy collected from a blistery lesion revealed an infiltrate of Virchow cells, superficial and deep necrotizing vasculitis of small vessels, associated lobular panniculitis (ENL) and necrosis all over the dermis and part of the hypodermis (Figure 2). The bacilloscopic index was 6+,
Figure 2. Vasculonecrotic reaction in leprosy: A, B (Case 1): early necrosis of the epidermis with pronounced upper dermis edema is seen (A), as well as necrotizing vasculitis and a mixed infiltrate of lymphocytes, macrophages and neutrophils (B); C, D (Case 2): there is epidermal necrosis with subepidermal cleft in the process of reepithelization. An infiltrate of foam cells and neutrophils is spread in the dermis (C) with necrotizing vasculitis (D); H\&E, original magnification $\mathrm{x} 100$ (C), x 640 (B, D), x 400 (A).
A
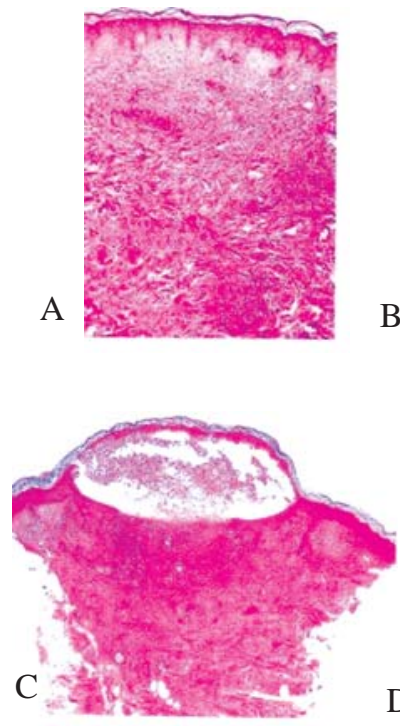

B

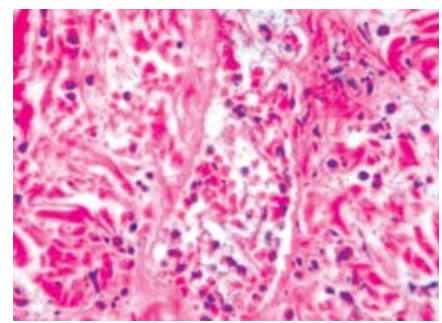

D

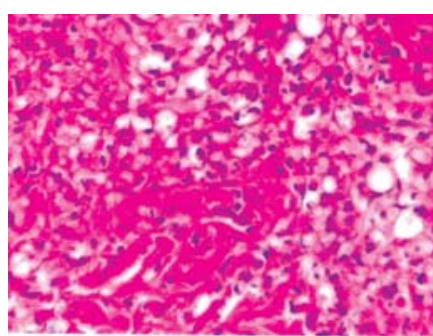


Figure 3. Erythema multiforme-like lesions on the lower extremity that occurred in the course of diffuse lepromatous leprosy treatment (Case2).

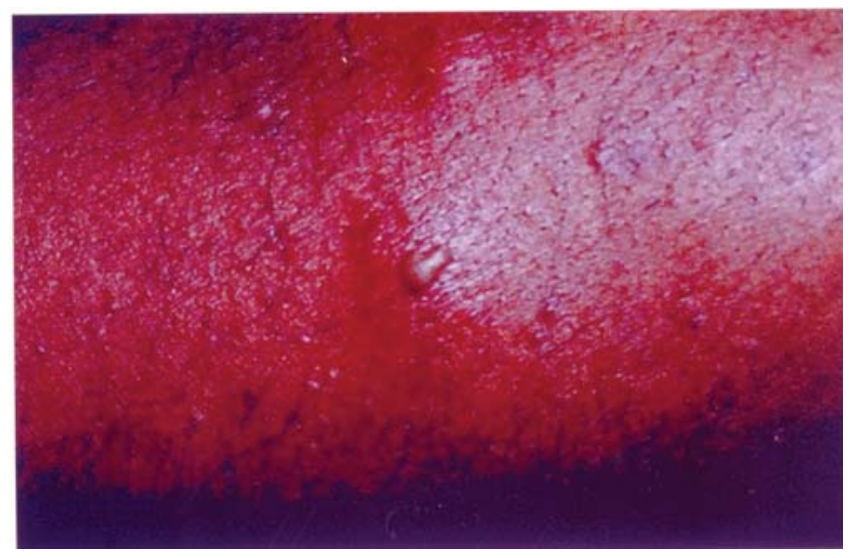

with whole and fragmented bacilli. He was hospitalized and thalidomide (300 mg/day) and prednisone ( $80 \mathrm{mg} /$ day) were prescribed, in addition to the multidrug therapy plan. After he was discharged, these dosages were gradually reduced. Six months later the use of thalidomide, $50 \mathrm{mg} /$ day, was suspended. A few days later he presented very painful erythema nodosum and erythema multiforme lesions (Fig. 3) on lower and upper limbs. In the course of disease he has presented, for four years, persistent erythema nodosum reactions, with or without ulcerations. The blisters healed resulting in atrophic hypochromic scars with hyperchromic borders.

\section{Discussion}

LP is a VN that occurs only in patients with diffuse forms of leprosy, in its pure and primitive or secondary form $[2,8,10,21]$. The literature review shows that some authors use the term LP for any VN developed in leprosy patients, while others refer to LP as a synonym of type II reaction [14,16-19].

Latapi, at the V International Leprosy Congress held in Havana, in 1948, already warned about the improper use of LP term for patients with other forms of multibacillary leprosy, who developed blisters and ulcerations, but did not present Lucio leprosy [2,9].

Patients with type II reaction may present extensive eschars resulting from vasculonecrotic phenomena that are confused with LP.

The clinical characteristics of leprosy in reaction with vasculitis are: 1) In LP, erythematous spots appear without localized infiltrations (diffuse leprosy that never presents papules, plaques or lepromas in the course of disease) and evolve into small superficial ulcerations, generally triangular or angular, that heal leaving atrophic and hypochromic scars; 2) In ENL, vasculonecrotic lesions with eschars are formed. Ulcers are deep and result in fibrotic, hypertrophic and radiated scars. On the other hand, patients with Lucio leprosy may develop ENL, after treatment is begun and when the typical necrotizing erythematous lesions begin to diminish. Patients with this form of leprosy may quickly present both types of reaction.

Thus, LP seems to be a reaction triggered by antigens of whole bacilli, potentially viable, in individuals genetically capable of identifying them, but with depressed cell-mediated immunity.

Although there are histological elements suggestive of LP (such as superficial form of vasculitis and, consequently, superficial necrosis of the skin), this denomination should be employed only under anatomoclinical correlation, that is, with the information that it is a necrotizing erythema in patients with the diffuse form of the disease, without localized infiltrations.

The histological findings of the patients here presented clearly illustrate that, as the clinical forms of leprosy are spectral, so are the vasculonecrotic leprosy reactions. LP, with all the described characteristics, would be located at one of the spectral poles, and the erythema nodosum reaction with vasculonecrotic phenomena associated with the multibacillary forms of disease, at the other.

In the first case, the histological findings were closer to those described in LP and the patient did not present systemic signs, such as fever or arthralgia. However, the clinical presentation of Hansen disease was that of infiltrated plaques and multidrug therapy had been used for one year. In addition, improvement has been achieved with the use of thalidomide. In the second case, the patient presented a diffuse form of leprosy, still untreated. Moreover, the features in the reactional picture, as much as lesions distribution and the aspect of the scars pointed to LP. Furthermore, a classical erythema nodosum developed after the treatment was started. By other side, histological findings were those of a dermal-hypodermal vasculitis associated with ENL and the patient had fever and pain in the lesions.

Moschela reported six cases of leprosy reaction with eschars in 1967 [14]. Two patients exhibited what he called "an unusually severe type of LP". Extensive scars resulted on the extremities, similar to the VN of the nodosa leprosy. Additionaly, the cutaneous eruption of other two patients incorporated clinical features of ENL and LP, which the author compared to allergic vasculitis of Ruiter.

An aspect that should be highlighted in the first case is the absence of foam cells in the cellular infiltrate, which is a clue for leprosy etiology in cutaneous necrotizing vasculitis. The patient was immunodeficient due to the chronic use of high doses of corticosteroids for treatment of ENL. The histological findings illustrate the need to consider leprosy diagnosis in necrotizing vasculitis, even when Virchow's cells are not found in the infiltrate.

The adequate characterization of these phenomena is important and the indiscriminate designation of disorders as LP should be avoided. However, there is difficulty in the classification of reactional states in these multibacillary leprosy 
patients. The emphasis on the spectral character of these reactions may help in the interpretation of histological findings. It may, as well, have therapeutic implications, justifying the use of thalidomide in patients that do not have the polar expression of LP. The validation of such hypotheses will depend on further and more comprehensive randomized studies.

\section{References}

1. Jollife D.S. Leprosy reactional states and their treatment. Br J Dermatol 1977;97:345-52.

2. Rodrigues O. Lepra de Lucio, historia e concepto. Dermat Rev Mex 1978;22:117-40.

3. Souza C.S., Roselino A.M.F., Figueiredo F., Foss N.T. Lucio phenomenon: clinical and therapeutic aspects. Int J Lepr Other Mycobact Dis 2000;68:417-25.

4. Marchese L.M., Marchese A.J.T., Rivitti E.A. Hanseníase. In: Veronesi R, Focaccia R, editors. Tratado de Infectologia. 2nd ed. São Paulo (Brasil): Livraria Atheneu Editora; 2002. p. 714-35.

5. Sampaio S.A.P., Rivitti E.A. Hanseníase. In: Dermatologia. 2nd ed. São Paulo (Brasil): Editora Artes Médicas; 2000. p. 467-88.

6. Talhari S., Neves R.G. Hanseníase. 3rd ed. Manaus (Brasil): Gráfica Tropical; 1997.

7. Lucio R., Alvarado I. Opusculo sobre el mal de San Lazaro o elephantiasis de los Griegos. México: Murguía e Cia; 1852.

8. Harter P., Mong-Don. Formes scarotiques d'erythema nodosum leprosum et leurs relations avec le phénomène Lucio. Bull Soc Pathol Exot 1962;6:993-1024.

9. Saul A., Novales J. Lucio- Latapi leprosy and the Lucio phenomenon. Acta Leprol 1983;1:115-32.

10. Latapi F., Zamora A.C. The "spotted' leprosy of Lucio (la lepra manchada de Lucio): An introduction to its clinical and histological study. Int J Lepr 1948;16:421-30.
11. Bernadat J.P., Faucher J.J., Huerre M. Diffuse lepromatous leprosy presenting as cutaneous vasculitis: Lucio phenomenon. Ann Dermatol Venereol 1996;123:21-3.

12. Baez M. Nota preliminar sobre la histopatología de las manifestaciones cutáneas de la "forma de Lucio" de la lepra. Rev Inst Salubr Enferm Trop 1941;2:245-58.

13. Pursley T.V., Jacobson R.R., Apisarnthanarax P. Lucio phenomenon. Arch Dermatol 1980;116:201-4.

14. Moschella S.L. The lepra reaction with necrotizing skin lesions: a report of six cases. Arch Dermatol 1967;95:565-75.

15. Rea T.H., Levan N.E. Lucio phenomenon and diffuse non nodular lepromatous leprosy. Arch Dermatol 1978;114:1023-8.

16. Kamp H., Leiker D.L., Frenken J.H. The relation between the Lucio phenomenon and cutaneous allergic vasculitis (Ruiter). Int J Lepr 1962;30:138-51.

17. Pereira Jr. A.C. Hanseníase de Lucio. An Bras Dermatol 1993;68:3340.

18. Saoji V., Salodkar A. Lucio leprosy with Lucio phenomenon. Indian J Lepr 2001;73:267-72.

19. Tappa D.M., Karthikeyan K., Kumar B.J. Is it Lucio leprosy with Lucio phenomenon or something else? Indian J Lepr 2002;74: $161-6$

20. Ang P., Tay Y.K., Ng S.K., Seow C.S. Fatal Lucio phenomenon in 2 patients with previously undiagnosed leprosy. J Am Acad Dermatol 2003;48:958-61.

21. Ackerman A.B. Histologic Diagnosis of Inflammatory Skin Diseases. Philadelphia (PA): Lea \& Febiger; 1978. p. 344-5.

22. Rea T.H., Ridley D.S. Lucio phenomenon: a comparative histological study. Int J Lepr 1979;47:161-6.

23. Bakos L., Correa C.C., Bergmann L., et al. Antiphospholipid antibodies thrombotic syndrom misdiagnosed as Lucio phenomenon. Int J Lepr Other Mycobact Dis 1996;64:320-3.

24. Sehgal V.N. Lucio's phenomenon/ erythema necroticans. Int J Dermatol 2005;44:602-5. 